\title{
Augmented and Virtual Reality for Engineering Education
}

\author{
Jaroslav Cibulka ${ }^{1}$ George Anthony Giannoumis ${ }^{2}$ \\ ${ }^{1}$ Department of Electronics Engineering, ${ }^{2}$ Department of Computer Science, Oslo and Akershus University College of \\ Applied Sciences, Norway, \{jaroslav.cibulka, gagian\}@hioa.no
}

\begin{abstract}
Research on the application of augmented and virtual reality (AVR) in education shows that students selfmotivation and performance increases as well as their attractiveness to new ICT-enhanced classes. The aim of this article is to explore the use of AVR as an engaging learning tool for engineering education and to present a framework for an AVR-lab for engineering education. The AVR-lab will encourage teachers to adapt classroom practices for state-of-the-art lectures that integrate AVR educational technology. The graduates of AVR-enhanced curriculum will attain new competencies in AVR, which industry analysts anticipate are vital for the $21^{\text {st }}$ century labour market.
\end{abstract}

Keywords: Augmented Reality (AR), Virtual Reality (VR), Mixed Reality (MR), Engineering Education Pedagogy, Science, Technology, Engineering and Mathematics (STEM), Research-based Learning, Metalearning, Technology-Enabled Active Learning (TEAL)

\section{Introduction}

To encourage interest of students and increase the attractiveness of engineering as a field of study remains a long-term challenge in the Norwegian education system. This article argues that this challenge may be remediated through the use of research-based learning methods, (NationalResearchCouncil, 2012, Singer and Smith, 2013, Nehm, 2014).

The augmented and virtual reality (AVR)-lab project at Oslo and Akershus University College of Applied Sciences originates from the idea of constructivistoriented pedagogy established in a technology-enabled learning environment (TEAL) (Shieh, 2012). Scholars have shown that technology-enhanced constructivist pedagogy improves students' non-test learning outcomes - e.g., interest in classes, labs and extracurricular science activities (Shieh, 2012). Consequently, student achievement (performance, higher learning outcomes) can provide motivation for teachers to change traditional teaching practices (structured lectures, note-taking) and teaching beliefs, allowing for the integration of new technology - i.e., state-of-the-art lectures with integrated educational technology.

The AVR-lab project aims to encourage teachers to use new information and communication technology (ICT) pedagogical tools in teaching and learning. This article argues that several mechanisms including communication and awareness, peer collaboration, evidence of improved student performance, and support from experts may help teachers to transform traditional instruction methods (structured lectures, note-taking) and adopt state-of-the-art lectures that integrate ICT.

This paper also relates to research on active learning methods such as the Flipped Classroom (FC), including methods to evaluate the study progress. Scholars have reported significant performance increase for students from the use of FC methods (Moravec et al., 2010, Day and Foley, 2006).

In comparison with typical definitions of $\mathrm{FC}$ methods (Bishop and Verleger, 2013), this article focuses on interactive and augmented learning resources (eBooks, exercises, games) instead of passive sources, such as instructional videos (asynchronous video lectures).

The AVR-lab aims to promote the practical application of active ICT-based pedagogy in teaching. Hence this article is dedicated to promoting ICTenhanced cooperative learning using the FC, problembased learning and meta-learning. Models of problembased learning suggest that students gain topic-specific knowledge and skills related to meta-learning by engaging in activities that simulate "real-world" contexts and challenges. Research refers to metalearning as an experiential process where students internalize norms, values and practices related to knowledge and skills acquisition (Rose et al., 2005).

In traditional approaches to learning, educational institutions treat the student as an object in the teaching process - i.e., the student is only a recipient of knowledge and information without any active role (Rose et al., 2005). Some scholars have argued that meta-learning provides a basis for students' to change their identity from recipients to creators of knowledge and understanding (Rose et al., 2005). As such, metalearning may promote "employability" by enhancing self-efficacy and resilience among students. In the context of the FC, the roles, identities and implicit norms, values and expectations of students and teachers may act to subvert the implementation of the FC approach (Hagerup, 2017).

However, research has also shown that students experience barriers to education in curriculum design, teaching methods and learning resources (Coppola et al., 2015, Nicholas et al., 2014, Boles and Whelan, 2016, Litzinger et al., 2011). 
According to (Rose et al., 2005) the Universal Design for Learning (UDL) is a reference model that guides educational practices, and aims to identify and remove barriers in educational methods, curricula and teaching materials. Taking a cue from research carried out on brain activity and the adoption of education technology, the UDL model provides the following guidelines:

- Representing the information in multiple formats and on different media.

- Providing students with multiple paths.

- Promoting many possibilities for expression and providing diversified ways to motivate students and arouse their interest.

UDL also frames learning as a process that can be designed to be accessible and inclusive for all students. The three principles stated above are supported by ICT to improve the learning process as follows:

- allow the manipulation and control of the learning environment.

- offer multi-sensory alternatives for learning materials.

- allow greater personal autonomy, especially for students with disabilities, such as attention and learning disabilities or sensory disabilities

- provide meaningful access to learning for all students by enabling students to grasp abstract concepts more fully.

This article argues that the combination of UDL and new ICT technologies in education can enable and empower students across the diversity of the human experience.

\section{Need for research}

Research shows that there is a need for continuous improvement in teaching, focusing on development of feedback culture and the use of new educational methods and tools (Deslauriers et al., 2011, Froyd et al., 2012, Singer et al., 2012, Nicol, 2010).

Currently, the textbooks and digital textbooks constitute the main source of learning materials (Vasileva et al., 2016, Hilton, 2016, Fan et al., 2013, Beetham and Sharpe, 2013). Nonetheless, research shows that students provided with only textbooks are less prepared for class than students provided with optional video lectures (de Grazia et al., 2012). Furthermore, students do not generally complete reading assignments (Sappington et al., 2002).

Textbooks are a passive source of information, in particular abstract terms, relationships, concepts, principles and processes, that lack multimedia interactivity - i.e., animations, visualizations and active simulations. Furthermore, feedback mechanisms, which are essential for improving learning outcomes, are also missing.
This article suggests updating pedagogical and curriculum approaches by transforming learning materials using state-of-the-art multimedia - e.g., using AVR, and Mixed Reality (MR). Student's attention and motivation are key factors for academic performance (Savage et al., 2011, Panisoara et al., 2015, Harandi, 2015, Law et al., 2010, Mendez and Gonzalez, 2011). Hence the aim is to encourage active learning by delivering interactivity into traditionally passive learning approaches and materials - e.g., lectures and textbooks.

Gamification in engineering education has not been fully adopted in schools, although the benefits of gamification have been shown in other fields (Pedreira et al., 2015, Dubois and Tamburrelli, 2013, Vasilescu, 2014, Hamari et al., 2014). Learning is best achieved through experiences - i.e., by using gamification to make tasks challenging and more engaging (Hamari et al., 2016, Ibáñez et al., 2014, Li et al., 2012, Barata et al., 2013b). Gamification supports peer-to-peer collaboration, social interaction and transcultural communication (Ducheneaut and Moore, 2004, Thorne, 2008, Thorne et al., 2009). Scholars have presented an AR crossover gamified design for engineering education in high school (Salman and Riley, 2016). Research has also posed a framework for using MR in gamification to assist teaching and learning in ICT (Muñoz et al., 2016). Active engagement and game challenges lead to improved learning processes and student outcomes (Guillén-Nieto and Aleson-Carbonell, 2012, Nicholson, 2015, Barata et al., 2013a, Domínguez et al., 2013, Clark et al., 2011).

MR provides immersive and engaging experiences through creative problem solving (Gardner and Elliott, 2014, Lindgren et al., 2016, Janßen et al., 2016, Thornhill-Miller and Dupont, 2016). MR has the potential to be a transformative technology in education - i.e., the ability to evoke empathy and the ability to trick the brain into experiencing another environment as real.

Social media are not implemented in curriculum although they can play important role as a beneficial infrastructure in learning processes (Krokan, 2012). Sharing allows students to collaborate and compete on assignments. Furthermore, social media often supports intercultural adaptation (Sawyer, 2011, Kosinski et al., 2015).

MR allows users to perceive the real world while virtual elements are superimposed upon or composited with the real world in real-time. Therefore, this article proposes to implement MR technologies to enhance learning, which may be applicable as an educational technology in various engineering courses.

The AVR-lab promotes the inclusion of new technology, teachers and all students - i.e., the target audience comprises students who experience barriers using traditional learning materials, students not engaged in engineering as a field of study, and students 
with disabilities. Research has yet to examine the usability and accessibility of MR educational technologies for students with physical, sensory or cognitive disabilities.

Demands for MR-competences are increasing in the labour market and industry in Norway (Urke, 2016, Armstrong, 2017). However, MR as a pedagogical tool has yet to fulfill these demands and has yet to be fully adopted in the Norwegian education system. One exception is the one year programme in AVR at Høgskolen i Innlandet (INN, 2017). Nevertheless, governmental and institutional support for using AVR in education has yet to fully emerge. The Norwegian technology sector and entrepreneurs have yet to fully embrace MR as an educational technology and a viable business venture.

Regarding engineering education in higher education, a survey has been carried out at HiOA based on data from internal, external and student reports (Cibulka, 2017). The survey reveals the following common problems: fixed learning style; non-inclusive education; lack of motivation and engagement; less graduates; infrastructure issues; high drop-out rate; lonely students; low competence prerequisites from high school; lack of teacher's feedback; high students-to-faculty ratio; staff shortage; overworked staff; lack of research and development (R\&D) activities; lack of student R\&D extracurricular activities; lack of supervision; low attendance in lectures; labs and group classes; low levels of encouragement; equipment issues; lack of adoption of recent educational technology; lack of clarification of concepts and theories; poor results in exams (high failure-rate); lack of applicants, low recruitment, lack of attractiveness, lack of uniqueness; students have personal obligations; teachers missing tools (technology gap, training gap); teacher's knowledge gap; decisionmakers missing knowledge; equipment cost; environmental load.

Engineering in higher education also experiences a high drop-out rate in mathematics (58\% at $\mathrm{HiOA}$ ). Research shows the economic benefit for the Norwegian economy if fewer students drop-out - i.e., approximately 1 million NOK per student (Falch et al., 2009, E24, 2013, Tunstad, 2013, Holstad, 2016). Furthermore, higher education institutions lose income for each student who fails a course and who drops out of a degree program.

\section{State-of-the-Art}

MR has been proven as efficient educational tool in many recent academic and magazine articles. A search in both popular and scientific literature has been conducted. Positive experiences with AVR in engineering education have shown that students selfmotivation and performance increases as well as an attractiveness of the new ICT-enhanced classes.
Pearson, the leader in educational courseware, collaborate with Microsoft on MR learning content for colleges, universities and secondary schools (Overland, 2016). (Kosowatz, 2017) summarized current engineering applications (civil eng., manufacturing, mining, maintenance, medical) of MR and its further potential. (Park, 2016) presented MR platform Peer (internet-enabled sensors and headset) for middle school students allowing interaction with visualized abstract concepts and complex forces.

(Wu et al., 2013) presented current AR technologies used in education as a productive concept for educators, researchers, and designers. Three categories of instructional AR approaches to help students in learning are presented: roles, tasks and locations. The solutions for AR-related challenges for educators and students are also proposed, i.e. technological (multiple devices), pedagogical and learning issues (cognitive overloading, complex tasks).

(Kirner et al., 2012) presented a concept of AR multiple-point $3 \mathrm{D}$ artifacts allowing precise action point interactions and thus reduce the amount of markers. The empowered artifact with smart AR reactions is an authoring tool with use in education and cognitive rehabilitation. Tests shown its low cost, availability, user-friendly interfaces, multi-sensory, tangible interaction and non-demanding dexterity.

(Gutiérrez Martín and Meneses Fernández, 2014) presented a state-of-the-art review of AR in higher education in engineering, training and multimedia. This paper practically demonstrated its benefits in comparison with traditional instructional learning. AR effects enhances, motivates and stimulates the learning process by interacting on the augmented environments.

This paper presents a state-of-the-art review of AVR in education of Science, Technology, Engineering and Mathematics (STEM). The use of MR-pedagogy in engineering education was explored, particularly in chemistry, physics, automation, electrical, civil and mechanical engineering.

Ad electrical eng., (Martín-Gutiérrez et al., 2015) presented empirical study of 3 AR-Apps, incl. interactive learning scenarios. Tests were carried out with students of electrical engineering, specifically electrical machines course. Both autonomous studying and collaborative lab practices were evaluated positively (in usability and feedback surveys). The need for a teacher's assistance was reduced.

\section{a) ElectARmanual}

Authors tested AR-manual as a solution for overcrowded lab for electric machines, incl. 3D models and animations, wiring diagrams and sounds (MartinGutierrez et al., 2012). The App assists with sequential instructions to fulfill different tasks, e.g. installations and configurations of electrical machines. 


\section{b) ELECT3D}

This Android AR-App enhances reading and comprehension of circuit diagrams, drawings, electrical symbols (both complex and realistic) and images. The App is universal since it uses extended library of normalized standard symbols and objects. AR is performed "marker-less", i.e. by means of cloud of points (normalized symbol).

\section{c) ElectAR_notes}

In order to explain abstract (invisible) and difficult topics, principles and concepts in electrical engineering (vectors, electromagnetism, ferromagnetism, electrical machines), the notes book (Basic Electrical Machines) were enhanced with AR content, e.g. images, 3D objects, 3D animations; audio, video and text explanations. Such upgraded and interactive notes led to better interlink between theoretical (abstract) and practical teaching. The AR-notes have double AR-mark, i.e. both marker-less image and fiducial $4 \times 4$ AR-mark.

(Desai et al., 2013) included interactive features between multiple virtual electrical 3D components to complete and simulate simple circuits. Users appreciated understanding the causal relationship based on the changes made to the parameter of the 3D electrical components. (Souza and Kirner, 2012) presented AR-tool to practice simple circuits tasks related to electromagnetism.

Ad automation, (Frank and Kapila, 2017) integrated MMR (tablet) to interact with motor test-bed in lab activities. Students demonstrated improvement in their knowledge of dynamic systems and control concept.

Ad Physics, (Chi-Poot and Martin-Gonzalez, 2014) presented using AR in learning of Euclidean vectors properties. The system aids the user to understand physical concepts, such as magnitude and direction, along with operations like addition, subtraction and cross product of vectors. Kinect sensor was used to visualize virtual components merged in a userinteraction (body interactive) environment. Users were able to virtually create vectors with different magnitudes and directions, and visualize their properties and operations.

Ad Chemical engineering, (Andrade et al., 2014, Maier and Klinker, 2013b, Maier and Klinker, 2013a, Maier and Klinker, 2013c) demonstrated a haptic wireless hand held device, i.e. an AR cubic-marker tool, and the tracking software "Augmented Chemical Reactions". This tool enables 3D molecules visualization, visualizing chemical properties, spatial relations and free direct manipulation with 3D interaction methods. The user immersion in chemistry learning had been improved, in comparison with a $2 \mathrm{D}$ representation in textbooks and molecular formula. The included chemical dynamics simulation helps to grasp the abstract internals of chemical reactions (dynamics of the atoms in and between molecules). This AR tool also helps researchers in prototyping, developing and understanding new chemical molecules. Gesture control (a self-tuning gesture recognition algorithm) allows prototyping with creating multiple bonds between two virtual molecules.

(Cai et al., 2014) presented an empirical case study with interactive 3D AR-models to control and visualize abstract chemical structures, microstructures, composition of substances and concepts. Study also included set of inquiry-based AR learning tools. Data analysis has shown the AR tool improved cognitive performance and is effective for low-achieving students.

Ad mechanical eng., Autodesk and Microsoft integrates CAD software Fusion 360 into collaborative MR-app "FreeForm" for HoloLens, (Gardiner, 2015).

EON Reality, the worldwide leader in the field of interactive training (Cheben, 2017), and educational software (Singletary, 2017), presented AR Diesel Engine Training (Hio, 2016).

(Martín-Gutiérrez, 2011, Gutiérrez Martín and Meneses Fernández, 2014) introduced an augmented book for mechanical engineering course "L-Elira". The virtual machine elements are represented by matching technical card containing information, e.g. use, rule number, standard element designation, graphic information, photorealistic images and an AR marker. AR fiducial marker allows visualization and animation of the 3D model. The authors reported in (Gutierrez and Fernandez, 2014) a better academic results and motivation of the first year mechanical engineering students. The exam results showed a significant statistical difference between academic performances of two groups (AR and classical notes), proving to be higher in the experimental group (AR); this group also showed a higher level of motivation than the control group (classical notes).

(Martín-Gutiérrez et al., 2010, Gutiérrez Martín and Meneses Fernández, 2014) introduced an augmented book AR-Dehaes for improving spatial abilities of mechanical engineering students by providing 3D virtual models and visualization tasks. A validation study of the remedial course confirmed positive impact on students' spatial ability.

(Rizov and Rizova, 2015) presented the benefits of using AR in higher education, by measuring outcomes (improved results) of the students which used AR as a teaching tool in the mechanical engineering course.

Ad Civil eng., Microsoft, Trimble and University of Cambridge collaborate towards MR-apps for MS HoloLens (Scialom, 2017), e.g. SketchUp Viewer (Vardhan, 2016). 
(Vassigh et al., 2016) presented AR-app AR-SKOPE for civil engineering education with integrated Building Information Modelling, showing the building's mechanical system information overlaid on the real building.

(Shirazi and Behzadan, 2015) presented a building structure model assembly using wooden blocks, equipped with AR-markers in order to teach abstract construction and civil engineering topics in a practical manner. This AR-based pedagogical tool led to a better performance, collaboration, communication and autonomous learning experience. Students in the test session worked in groups and received instructions from the virtual avatar, and scanned the tracking image attached to each building element to access information.

(Kirner et al., 2012) presented AR Spatial Tutor, a tool for interaction with panels and mockups (Styrofoam) using AR, to expose AR-layer (dynamic content), 3D objects, annotations, sounds and animations. Interactive points have multiple information elements that allow the expansion of contents or the fulfilling of different types of users.

As conclusion, the State-of-the-Art review revealed current trends in AR-Apps for engineering education. Good results from the exams and feedback surveys indicate beneficial use in engineering degrees. ARapproach can be applied in different engineering courses due to similar didactics and software. However, complex dynamic simulations are still missing in current AR-apps. Simulations should be implemented since it is important to see and understand any system response. For example, to study electrical circuits it is vital to understand the effects of value adjustment or component configuration. The training framework including instant learning feedback of learning outcome is also missing.
Current learning approaches does not reflect each individual student's skills and learning style. The ARApp should include feedback learning system with interactive examples and tasks. Such feedback is beneficial for student/teacher, allowing them to track the learning effectiveness and focus on difficult parts. Utilization of advances in Biofeedback and Artificial Intelligence (AI) is missing.

\section{Concept of AVR-lab "Mi-ity"}

We will utilize novel mobile MR solutions. We will focus on an engineer from the life-span perspective, i.e. all age scholar groups from kindergarten towards adult vocational training. We will establish hub "Mi-ity", the mobile MR innovation hub for lifelong engineering education, at HiOA, together with our key industrial partners. The hub concept is illustrated in Figure 1.

We will test both engineering and non-engineering students to reveal if MR has positive learning effect (high learning outcomes) regardless background and interest. Mi-ity targets 3 user groups in lifelong spectra: students, teachers and decision makers. Testing and validation of MR-apps will be conducted in the selected pilot courses. We will conduct experiments in cooperation with our research and user partners.

\subsection{Development of MR-education}

The learning modules with MR will be designed based on the didactic model presented by (Bjørndal and Lieberg, 1978). Didactic model is used to design all the learning modules in a course.

Universal Design for Learning (Rose et al., 2005) is a reference model that will guide the development of educational MR-contents and practices, i.e. enables the learning process to be more accessible, universally

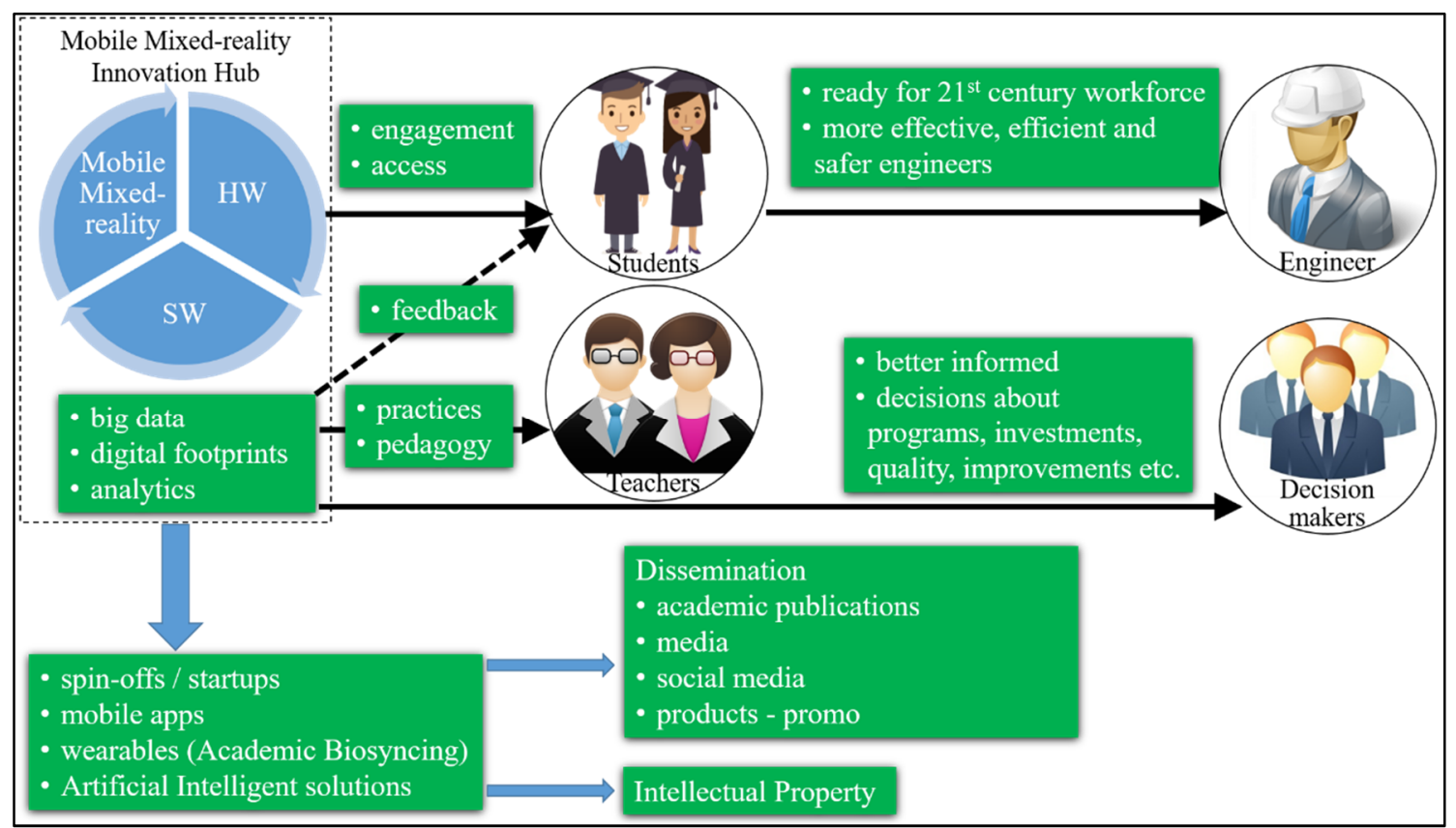

Figure 1. Concept of Mi-ity: the mobile mixed-reality innovation hub for lifelong engineering education 
designed and inclusive for all students, incl. with learning or sensory disabilities.

MR platform comprises challenging tasks with gamification features. It covers engineering-related topics: mathematics, mechanical, electrical, control, biochemistry etc.

\subsection{MR tool "MixRALF"}

The new MR tool will cover virtual teaching contents, a multi-platform and interactive MR-Apps, learning feedback system, dynamic simulations, biofeedback and integration to social media.

We will develop "MixRALF", the mobile mixedreality system with the real-time autonomous learning feedback. MixRALF comprises MR, academic biosyncing (biometric wearables) and AI, see Figure 2. This unique combination has not been reported yet.

MR educational and engineering-related content will be developed in multiplatform tools, e.g. EON Studio, Unity 3D and Unreal. The MR content is scalable in both platform compatibility (smartphone $\leftrightarrow$ headset) and contents (kindergarten $\leftrightarrow$ university).

Microsoft HoloLens, a self-contained wearable holographic computer, will be used as mobile MR headset. We will also test wireless HTC Vive and smartphones.

We will further enhance the immersive MRexperience with an academic biosyncing. Academic biosyncing is a new concept of bio-mechanical symbiosis where scholar and machine are in a reactive, performance-augmenting loop, by means of biofeedback (biometric data, wearables) and AI, see Figure 2. Similarly to athletic biosyncing, it is expected that scholar change learning routines, i.e. enters into an automatic reactive state.

We will use biometric wearables to measure focus level, engagement, excitement or stress. Selected biometric wearables: Insight by Emotiv (EEG headset for brain activity); wristband E4 by Empatica (galvanic skin response - electrodermal activity sensor, cardiovascular features - blood volume pulse, heart beat, heart rate variability, blood pressure etc.), see Figure 3.

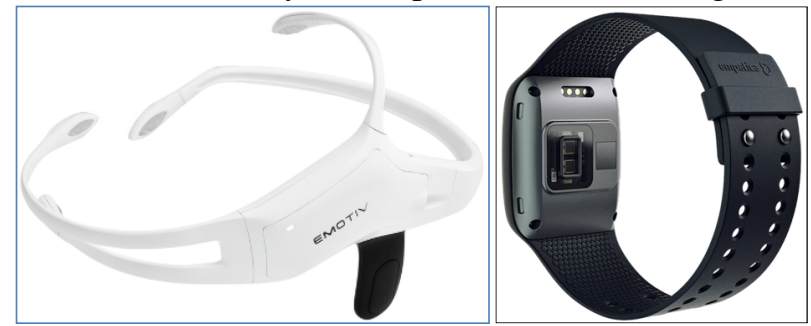

Figure 3: Emotiv Insight (EEG headset) and wristband Empatica E4 (electrodermal and cardiovascular activity)

Voice (tone), gesture (controlled commands) and facial reaction recognition is already possible with HoloLens. Eye movement tracking is possible with HTC Vive (Durbin, 2017), and will be integrated in the next version of HoloLens as well (Walker, 2017).

MixRALF system comprises "Big Data" problem to be solved by AI. Integrative AI, i.e. generative AI and MR, will provide awareness about cognitive state, focus level and mental preparedness, and thus improve educational experiences in combination with MR. AI can be in the form of virtual teacher, capable to recognize skills, learning style and mental state. He (AI) will customize the learning approach and contents accordingly, to fit each individual student, i.e. he will track and train focus, and track and improve educational experiences.

For this mission we have selected IBM Watson (Bluemix developer platform) as the best AI technology. It is an advance AI cognitive system, already successfully proven in educational experiments (Goel et al., 2015, Goel, 2016). HiOA is the first "WatsonUniversity" in Norway.

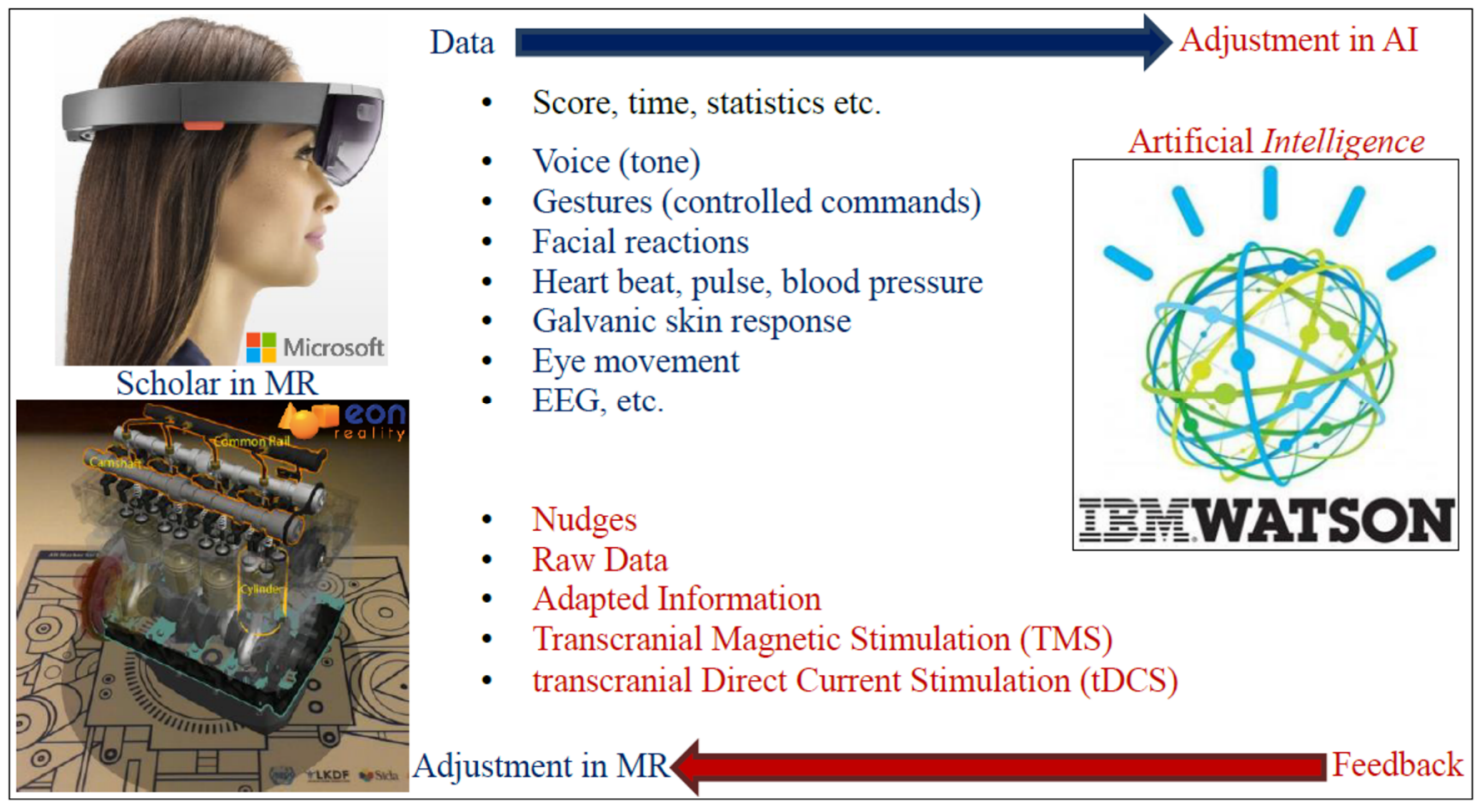

Figure 2. MixRALF - the mobile mixed-reality system with the real-time autonomous learning feedback 
AI will also utilize digital footprints to recognize student's personally traits and mental state by digital means, e.g. intelligence, basic emotions etc. (Lambiotte and Kosinski, 2014). Introverts tend to belong to fewer but larger and denser communities, while extroverts tend to act as bridges between more frequent, smaller, and overlapping communities.

(Kosinski et al., 2016) presented methods to extract patterns and build predictive models using large data sets of digital footprints (mining big data). (Youyou et al., 2015) demonstrated that AI can predict personality, based on digital footprints, automatically and more accurately than human (friend), i.e. without involving human social-cognitive skills. AI and digital footprints will further help to state the learning ability and thus help to select the optimal MR tool for the best learning outcome.

With the help of AI and biometrics the scholar will be able to respond to its learning environments and more fully realize its learning potential. Student become aware of its cognitive state, mental preparedness and focus level, and thus improve educational experiences. The whole-body wellness and overall activity will be tracked and better understood. AI will identify personal traits and mental states of a student.

MixRALF will track and evaluate student's performance with combination of qualitative (observation by AI) and quantitative data (score, time, task statistics, biometrics), and adjust the individual learning approach accordingly. For example, the system identifies if student is bored and thus offer him a more challenging tasks and engagement in his studies. It will also feature the dynamic difficulty, i.e. AI will adjust the difficulty of task instantaneously, based on the real-time feedback. Thus AI decrease the difficulty level for failing student in order to keep him engaged, motivated and prevent frustration, and vice versa, AI increases difficulty for prospering student.

MixRALF will output self-contained results about student's learning outcome and recommendation for improvement, i.e. includes feedback about scoring, time, interpretation of results and task statistics, e.g. design-related parameters such as cost, reliability, lifetime, stress strength etc. The feedback on learning progress will be available for students, teachers and decision makers, incl. comprehensive methodology to evaluate the study progress. The key performance indicators are learning outcomes, e.g. speed of learning.

\subsection{Expected benefits}

The potential for value creation is illustrated in Figure 4. Mi-ity will train next-gen students and teachers in the use of MR in educational settings and real pedagogical practice, i.e. reduce gap between education and new ICT.

Lab will provide rich, interactive, responsive and accessible learning experience. Real-time feedback and adjustment of learning scenario allows individual approach, i.e. for both students with disabilities and students with an over average mental capacity.

Mi-ity will promote active participation in lifelong learning process. Mi-ity enable faster adoption of Problem-based Learning and Flipped Classrooms by using MR-tools in interactive learning activities and teaching practice. MixRALF will increase the learning outcomes, i.e. students recognize, identify and grasp the knowledge, especially abstract concepts, faster and more meaningfully.

With AI training guidance the student will study independently and thus saves the teacher's time.

\begin{tabular}{|c|c|c|c|c|c|}
\hline Wearables & $\begin{array}{l}\text { Learning } \\
\text { Analytics }\end{array}$ & $\begin{array}{c}\text { Artificial } \\
\text { Intelligent } \\
\text { Solutions }\end{array}$ & eHealth & $\begin{array}{l}\text { Educational } \\
\text { Technology }\end{array}$ & $\begin{array}{l}\text { Emergency } \\
\text { Services }\end{array}$ \\
\hline $\begin{array}{l}\text { Novel User } \\
\text { Interfaces }\end{array}$ & Innovative & Technology & Ground-bre & Businesses & Gaming \\
\hline $\begin{array}{c}\text { Mobile } \\
\text { Applications }\end{array}$ & & Makerspace & Startup Ince & & $\begin{array}{l}\text { Industrial } \\
\text { Maintenance } \\
\text { and Safety }\end{array}$ \\
\hline $\begin{array}{l}\text { Inclusive } \\
\text { Education } \\
\text { Practices }\end{array}$ & & $\begin{array}{c}\text { Center for Research } \\
\text { Excellence }\end{array}$ & $\begin{array}{l}\text { Learning } \\
\text { Training } \mathrm{C}\end{array}$ & & $\begin{array}{c}\text { Nanodegrees } \\
\text { and } \\
\text { Certificates }\end{array}$ \\
\hline $\begin{array}{l}\text { Immersive } \\
\text { Active } \\
\text { Learning }\end{array}$ & \multicolumn{2}{|c|}{ New Knowledge } & \multicolumn{2}{|c|}{ State-of-the-Art Experience } & $\begin{array}{l}\text { Education } \\
\text { Technology } \\
\text { Courses }\end{array}$ \\
\hline Gamification & $\begin{array}{c}\text { Flipped } \\
\text { Classroom } \\
\text { Approaches }\end{array}$ & $\begin{array}{c}\text { Real-time } \\
\text { Formative } \\
\text { Assessments }\end{array}$ & MOOCs & $\begin{array}{l}\text { Summer } \\
\text { School } \\
\text { Courses }\end{array}$ & $\begin{array}{c}\text { Intensive } \\
\text { Training } \\
\text { Modules }\end{array}$ \\
\hline
\end{tabular}

Figure 4. Mi-ity - Value Creation Potential 
Teacher will have more time for creative work such as content development, class preparation, R\&D, publishing etc. Teacher will be able to provide closer individual feedback to the student and encourage his critical thinking, reflection and creativity.

Decision makers will get more and accurate information/knowledge to perform better decisions about programs, investments, quality and improvements.

Mi-ity will reduce drop-out rate and thus reduce high expenses related to the failure-rate. The new educational system will increase the attractiveness of engineering curriculum and thus improve the recruitment of applicants.

Students will become better engineers and meet the increasing demands for MR-competences in labour market and industry in Norway. MR-enhanced curriculum will result in faster and effective development of engineering competences, i.e. instrumental competences (analysis and synthesis skills, planning and organization skills, solving problems, managing information as well as taking decisions), personal competences (teamwork, workplace interpersonal relations skills, critical reasoning), systemic skills (autonomous learning, leadership, initiative, entrepreneur, motivation for quality) and spatial skills. Students become self-motivated, independent and competent professional, reducing the ad-hoc occupational training cost.

Project promotes entrepreneurship in education technologies (release new MR apps) by collaboration of partners, HW- and SW-related students.

MR replaces physical equipment and thus eliminate the safety risk, expenses and power. Training with virtual equipment decreases a fear for further real practice with e.g. electric circuits, soldering, welding etc. MR decrease demands and cost for physical infrastructure e.g. study rooms, labs, auditoriums. MR shifts physical learning space into a virtual learning environment, which also allows student's remote participation.

MR, gamification and social media will diminish the intercultural differences and support better cooperation and communication between peers with different cultural background.

\section{Conclusion}

The State-of-the-Art review revealed positive experiences with application of MR in engineering education. However, the recent solutions does not reflect advances in biofeedback wearables and AI, towards further improvement of learning feedback and outcome. Therefore we proposed a project concept of AVR-lab, where we will test the mobile MR in closedloop combination with biometrics and AI. We focus on improving student's learning performance and teacher's knowledge transfer in the lifelong perspective. The realtime learning feedback will tailor the educational approach to fit each student individually. The new autonomous learning system will allow independent study and thus save the teacher's time. Gamification of task challenges will create an attractive and motivational tool for the student. The new MR-enhanced curriculum will reflect the rapidly increasing competence demands for MR technology in the engineering industry and labor market in Norway.

\section{Acknowledgments}

The authors would like to thank assoc. prof. Tiina M. Komulainen for her valuable inputs.

\section{References}

Andrade, T. F., Maier, P., Quintas, M. R., Klinker, G. \& Restivo, M. T. Adding sensorial capabilities to the augmented chemical reactions application. 2014 11th International Conference on Remote Engineering and Virtual Instrumentation (REV), 26-28 Feb. 2014. 217-218.

http://dx.doi.org/10.1109/REV.2014.6784259

Armstrong, V. 2017. Teknologi som kan forandre verden. E24.

Barata, G., Gama, S., Jorge, J., Gon, D., \#231 \& Alves 2013a. Improving participation and learning with gamification. Proceedings of the First International Conference on Gameful Design, Research, and Applications. Toronto, Ontario, Canada: ACM. https://doi.org/10.1145/2583008.2583010

Barata, G., Gama, S., Jorge, J. \& Goncalves, D. Engaging Engineering Students with Gamification. 2013 5th International Conference on Games and Virtual Worlds for Serious Applications (VS-GAMES), 11-13 Sept. 2013 2013b. 1-8. https://doi.org/10.1109/VS-GAMES.2013.6624228

Beetham, H. \& Sharpe, R. 2013. Rethinking Pedagogy for a Digital Age: Designing for 21st Century Learning, Taylor \& Francis.

Bishop, J. L. \& Verleger, M. A. The Flipped Classroom: A Survey of the Research. 2013 ASEE Annual Conference, 2013 Atlanta. American Society for Engineering Education.

Bjørndal, B. \& Lieberg, S. 1978. Nye veier i didaktikken?: en innføring i didaktiske emner og begreper, Oslo, Aschehoug.

Boles, W. \& Whelan, K. 2016. Barriers to student success in engineering education. European Journal of Engineering Education, $1-14$. https://doi.org/10.1080/03043797.2016.1189879

Cai, S., Wang, X. \& Chiang, F.-K. 2014. A case study of Augmented Reality simulation system application in a chemistry course. Computers in Human Behavior, 37, 31-40. http://dx.doi.org/10.1016/j.chb.2014.04.018

Cheben, M. 2017. EON Reality Releases EON Enterprise Virtual Trainer (EVT) To Address Today's Growing Knowledge Gap In The Global Industrial Workforce. Marketwired.

Chi-Poot, A. \& Martin-Gonzalez, A. 2014. Euclidean Vectors in Physics Education Using Augmented Reality. In: DE PAOLIS, L. T. \& MONGELLI, A. (eds.) Augmented and Virtual Reality: First International Conference, AVR 2014, Lecce, Italy, September 17-20, 2014, Revised Selected Papers. Cham: Springer International Publishing. http://dx.doi.org/10.1007/978-3-319-13969-2_30

Cibulka, J. 2017. Problems in quality of engineering education at HiOA: Faculty of Technology, Art and Design (TKD), survey report. HiOA. 
Clark, D. B., Nelson, B. C., Chang, H.-Y., Martinez-Garza, M., Slack, K. \& D'angelo, C. M. 2011. Exploring Newtonian mechanics in a conceptually-integrated digital game: Comparison of learning and affective outcomes for students in Taiwan and the United States. Computers \& Education, 57, 2178-2195. http://dx.doi.org/10.1016/j.compedu.2011.05.007

Coppola, S. M., Madariaga, L. A. \& Schnedeker, M. H. 2015. Assessing Teachers' Experiences with STEM and Perceived Barriers to Teaching Engineering. 2015 ASEE Annual Conference \& Exposition. Seattle, WA: American Society for Engineering Education.

Day, J. A. \& Foley, J. D. 2006. Evaluating a Web Lecture Intervention in a Human\&ndash;Computer Interaction Course. IEEE Transactions on Education, 49, 420-431. http://dx.doi.org/10.1109/TE.2006.879792

De Grazia, J. L., Falconer, J. L., Nicodemus, G. \& Medlin, W. Incorporating ScreenCasts into Chemical Engineering Courses 2012 ASEE Annual Conference, 2012.

Desai, R., Dave, R., Mehta, R., Joshi, A. \& Benjamin, S. 2013. Interactive Circuits Using Augmented Reality. International Journal Of Scientific and Engineering Research, 4, 778-781.

Deslauriers, L., Schelew, E. \& Wieman, C. 2011. Improved Learning in a Large-Enrollment Physics Class. Science, 332, 862-864. https://doi.org/10.1126/science. 1201783

Domínguez, A., Saenz-De-Navarrete, J., De-Marcos, L., Fernández-Sanz, L., Pagés, C. \& Martínez-Herráiz, J.-J. 2013. Gamifying learning experiences: Practical implications and outcomes. Computers \& Education, 63, 380-392. http://dx.doi.org/10.1016/i.compedu.2012.12.020

Dubois, D. J. \& Tamburrelli, G. 2013. Understanding gamification mechanisms for software development. Proceedings of the 2013 9th Joint Meeting on Foundations of Software Engineering. Saint Petersburg, Russia: ACM. https://doi.org/10.1145/2491411.2494589

Ducheneaut, N. \& Moore, R. J. 2004. The social side of gaming: a study of interaction patterns in a massively multiplayer online game. Proceedings of the 2004 ACM conference on Computer supported cooperative work. Chicago, Illinois, USA: ACM. http://dx.doi.org/10.1145/1031607.1031667

Durbin, J. 2017. HTC Vive Is Getting A \$220 Plug-And-Play Eye Tracking Peripheral Next Month. UploadVR.

E24 2013. Professor: Elever forstår tall dårligere enn før. E24.

Falch, T., Johannesen, A. B. \& Strøm, B. 2009. Kostnader av frafall $\mathrm{i}$ videregående opplæring. TRONDHEIM: SENTER FOR ØKONOMISK FORSKNING AS.

Fan, L., Zhu, Y. \& Miao, Z. 2013. Textbook research in mathematics education: development status and directions. ZDM, 45, 633-646. https://doi.org/10.1007/s11858-013-0539$\underline{\mathrm{x}}$

Frank, J. A. \& Kapila, V. 2017. Mixed-reality learning environments: Integrating mobile interfaces with laboratory test-beds. Computers \& Education, 110, 88-104. https://doi.org/10.1016/j.compedu.2017.02.009

Froyd, J. E., Wankat, P. C. \& Smith, K. A. 2012. Five Major Shifts in 100 Years of Engineering Education. Proceedings of the IEEE, 100, 1344-1360. https://doi.org/10.1109/JPROC.2012.2190167

Gardiner, G. 2015. Microsoft HoloLens + Autodesk Fusion 360 $=$ Mixed Reality for Product Design and Engineering. In the Fold, Autodesk.

Gardner, M. R. \& Elliott, J. B. 2014. The Immersive Education Laboratory: understanding affordances, structuring experiences, and creating constructivist, collaborative processes, in mixed-reality smart environments. EAI Endorsed Transactions on Future Intelligent Educational Environments 1. https://doi.org/10.4108/fiee.1.1.e6
Goel, A. 2016. Using Watson for Constructing Cognitive Assistants. Advances in Cognitive Systems, 4.

Goel, A., Creeden, B., Kumble, M., Salunke, S., Shetty, A. \& Wiltgen, B. 2015. Using Watson for Enhancing HumanComputer Co-Creativity.

Guillén-Nieto, V. \& Aleson-Carbonell, M. 2012. Serious games and learning effectiveness: The case of It's a Deal! Computers \& Education, 435-448. http://dx.doi.org/10.1016/j.compedu.2011.07.015

Gutiérrez Martín, J. \& Meneses Fernández, M. D. 2014. Augmented Reality Environments in Learning, Communication and Professional Contexts in Higher Education. Digital Education Review, 26, 22-34.

Gutierrez, J. M. \& Fernandez, M. D. M. 2014. Applying Augmented Reality in Engineering Education to Improve Academic Performance \& Student Motivation. International Journal of Engineering Education, 30, 625-635.

Hagerup, N. 2017. Challenging the Auditorium: How to Flip a Classroom in a Room that cannot be Flipped? 19th International Conference on Engineering and product Design Education. Oslo.

Hamari, J., Koivisto, J. \& Sarsa, H. Does Gamification Work? -A Literature Review of Empirical Studies on Gamification. 2014 47th Hawaii International Conference on System Sciences, 6-9 Jan. 2014 2014. 3025-3034. https://doi.org/10.1109/HICSS.2014.377

Hamari, J., Shernoff, D. J., Rowe, E., Coller, B., Asbell-Clarke, J. \& Edwards, T. 2016. Challenging games help students learn: An empirical study on engagement, flow and immersion in game-based learning. Computers in Human Behavior, 54, 170179. https://doi.org/10.1016/j.chb.2015.07.045

Harandi, S. R. 2015. Effects of e-learning on Students' Motivation. Procedia - Social and Behavioral Sciences, 181, 423-430. http://dx.doi.org/10.1016/j.sbspro.2015.04.905

Hilton, J. 2016. Open educational resources and college textbook choices: a review of research on efficacy and perceptions. Educational Technology Research and Development, 64, 573590. https://doi.org/10.1007/s11423-016-9434-9

Hio, L. 2016. Augmented and virtual reality firm Eon Reality sets up R\&D centre in Singapore. The Straits Times.

Holstad, G. 2016. Forsker på drop outs. Adresseavisen.

Ibáñez, M. B., Á, D.-S. \& Delgado-Kloos, C. 2014. Gamification for Engaging Computer Science Students in Learning Activities: A Case Study. IEEE Transactions on Learning Technologies, 7, 291-301. https://doi.org/10.1109/TLT.2014.2329293

Inn. 2017. Add-On programme in Augmented and Virtual Reality at Høgskolen i Innlandet

Janßen, D., Tummel, C., Richert, A. \& Isenhardt, I. 2016. Towards Measuring User Experience, Activation and Task Performance in Immersive Virtual Learning Environments for Students. In: ALLISON, C., MORGADO, L., PIRKER, J., BECK, D., RICHTER, J. \& GÜTL, C. (eds.) Immersive Learning Research Network: Second International Conference, iLRN 2016 Santa Barbara, CA, USA, June 27 July 1, 2016 Proceedings. Cham: Springer International Publishing. https://doi.org/10.1007/978-3-319-41769-1_4

Kirner, C., Kirner, T. G. \& Cerqueira, C. S. 2012. Using Augmented Reality Artifacts in Education and Cognitive Rehabilitation. 39046

Kosinski, M., Matz, S. C., Gosling, S. D., Popov, V. \& Stillwell, D. 2015. Facebook as a research tool for the social sciences: Opportunities, challenges, ethical considerations, and practical guidelines. American Psychologist, 70, 543-556. http://dx.doi.org/10.1037/a0039210

Kosinski, M., Wang, Y., Lakkaraju, H. \& Leskovec, J. 2016. Mining big data to extract patterns and predict real-life 
outcomes. Psychological Methods, 21, 493-506. http://dx.doi.org/10.1037/met0000105

Kosowatz, J. 2017. Mixed Reality Changes How Engineers Work. The American Society of Mechanical Engineers.

Krokan, A. 2012. Smart laering - hvordan ikt og sosiale medier endrer laering, Fagbokforlaget.

Lambiotte, R. \& Kosinski, M. 2014. Tracking the Digital Footprints of Personality. Proceedings of the IEEE, 102, 19341939. http://dx.doi.org/10.1109/JPROC.2014.2359054

Law, K. M. Y., Lee, V. C. S. \& Yu, Y. T. 2010. Learning motivation in e-learning facilitated computer programming courses. Computers \& Education, 55, 218-228. http://dx.doi.org/10.1016/i.compedu.2010.01.007

Li, W., Grossman, T. \& Fitzmaurice, G. 2012. GamiCAD: a gamified tutorial system for first time autocad users. Proceedings of the 25th annual ACM symposium on User interface software and technology. Cambridge, Massachusetts, USA: ACM. https://doi.org/10.1145/2380116.2380131

Lindgren, R., Tscholl, M., Wang, S. \& Johnson, E. 2016 Enhancing learning and engagement through embodied interaction within a mixed reality simulation. Computers \& Education, 95 , $174-187$. http://dx.doi.org/10.1016/i.compedu.2016.01.001

Litzinger, T., Lattuca, L. R., Hadgraft, R. \& Newstetter, W. 2011. Engineering Education and the Development of Expertise. Journal of Engineering Education, 100, 123-150. https://doi.org/10.1002/j.2168-9830.2011.tb00006.x

Maier, P. \& Klinker, G. 2013a. Augmented Chemical Reactions: 3D Interaction Methods for Chemistry. International Journal $\begin{array}{llll}\text { of Online Engineering (iJOE), } & 9, & 80-82\end{array}$ http://dx.doi.org/10.3991/ijoe.v9iS8.3411

Maier, P. \& Klinker, G. Augmented chemical reactions: An augmented reality tool to support chemistry teaching. 2013 2nd Experiment@ International Conference (exp.at'13), 18-20 Sept. 2013 2013b. 164-165 http://dx.doi.org/10.1109/ExpAt.2013.6703055

Maier, P. \& Klinker, G. 2013c. Evaluation of an AugmentedReality-based 3D User Interface to Enhance the 3DUnderstanding of Molecular Chemistry. Proceedings of the 5th International Conference on Computer Supported Education (CSEDU-2013). SCITEPRESS (Science and Technology Publications,

Lda.). http://dx.doi.org/10.5220/0004349502940302

Martín-Gutiérrez, J. Proposal of methodology for learning of standard mechanical elements using augmented reality. 2011 Frontiers in Education Conference (FIE), 12-15 Oct. 2011 2011.

T1J-1-T1J-6 http://dx.doi.org/10.1109/FIE.2011.6142708

Martín-Gutiérrez, J., Fabiani, P., Benesova, W., Meneses, M. D. \& Mora, C. E. 2015. Augmented reality to promote collaborative and autonomous learning in higher education. Computers in Human Behavior, 51, Part B, 752-761. http://dx.doi.org/10.1016/j.chb.2014.11.093

Martin-Gutierrez, J., Guinters, E. \& Perez-Lopez, D. 2012. Improving Strategy of Self-Learning in Engineering: Laboratories with Augmented Reality. Procedia - Social and Behavioral Sciences, 532-839. http://dx.doi.org/10.1016/i.sbspro.2012.08.249

Martín-Gutiérrez, J., Luís Saorín, J., Contero, M., Alcañiz, M., Pérez-López, D. C. \& Ortega, M. 2010. Design and validation of an augmented book for spatial abilities development in engineering students. Computers \& Graphics, 34, 77-91. http://dx.doi.org/10.1016/j.cag.2009.11.003

Mendez, J. A. \& Gonzalez, E. J. 2011. Implementing Motivational Features in Reactive Blended Learning: Application to an Introductory Control Engineering Course.
IEEE Transactions on Education, 54, 619-627. https://doi.org/10.1109/TE.2010.2102028

Moravec, M., Williams, A., Aguilar-Roca, N. \& O'dowd, D. K. 2010. Learn before Lecture: A Strategy That Improves Learning Outcomes in a Large Introductory Biology Class. CBE-Life Sciences Education, 9, 473-481. http://dx.doi.org/10.1187/cbe.10-04-0063

Muñoz, J. C., Cowling, M. A. \& Birt, J. Using gamification and mixed reality visualization to improve conceptual understanding in ICT system analysis and design. 33rd Internatioal Conference on Innovation, Practice and Research in the Use of Educational Tehnologies in Tertiary Education, 2016 University of South Australia, Adeleide. 455-460.

Nationalresearchcouncil 2012. Discipline-Based Education Research: Understanding and Improving Learning in Undergraduate Science and Engineering, Washington, DC, The National Academies Press. https://doi:10.17226/13362

Nehm, R. H. 2014. Discipline-Based Education Research: Understanding and Improving Learning in Undergraduate Science and Engineering, by Susan R.Singer, Natalie R.Nielsen, and Heidi A.Schweingruber (Eds.). PB - National Academies Press, Washington, DC, USA, 2012. xi + 264 pp. ISBN 978-0-309-25411-3. Science Education, 98, 543-546. https://doi:10.1002/sce.21091

Nicholas, D. F., Senay, P. \& Paul, D. M. 2014. I'm Not the Creative Type: Barriers to Student Creativity within Engineering Innovation Projects. Indianapolis, Indiana: ASEE Conferences.

Nicholson, S. 2015. A RECIPE for Meaningful Gamification. In: REINERS, T. \& WOOD, L. C. (eds.) Gamification in Education and Business. Cham: Springer International Publishing. https://doi.org/10.1007/978-3-319-10208-5_1

Nicol, D. 2010. From monologue to dialogue: improving written feedback processes in mass higher education. Assessment \& Evaluation in Higher Education, 35, 501-517. https://doi.org/10.1080/02602931003786559

Overland, S. 2016. Pearson Announces Mixed Reality Pilots Designed to Solve Real World Learning Challenges at Colleges and Universities. Pearson Education.

Panisoara, G., Duta, N. \& Panisoara, I.-O. 2015. The Influence of Reasons Approving on Student Motivation for Learning. Procedia - Social and Behavioral Sciences, 197, 1215-1222. http://dx.doi.org/10.1016/j.sbspro.2015.07.382

Park, D. 2016. Introducing Peer-A Mixed Reality Educational Experience. Design Intelligence.

Pedreira, O., García, F., Brisaboa, N. \& Piattini, M. 2015. Gamification in software engineering - A systematic mapping. Information and Software Technology, 57, 157-168. http://dx.doi.org/10.1016/j.infsof.2014.08.007

Rizov, T. \& Rizova, E. D. 2015. AUGMENTED REALITY AS A TEACHING TOOL IN HIGHER EDUCATION.

Rose, D. H., Meyer, A. \& Hitchcock, C. 2005. The Universally Designed Classroom: Accessible Curriculum and Digital Technologies, Harvard Education Press, Cambridge.

Salman, F. H. \& Riley, D. R. Augmented reality crossover gamified design for sustainable engineering education. 2016 Future Technologies Conference (FTC), 6-7 Dec. 20162016. 1353-1356. http://dx.doi.org/10.1109/FTC.2016.7821781

Sappington, J., Kinsey, K. \& Munsayac, K. 2002. Two Studies of Reading Compliance among College Students. Teaching of Psychology, 29, 272-274. http://dx.doi.org/10.1207/s15328023top2904_02

Savage, N., Birch, R. \& Noussi, E. 2011. Motivation of engineering students in higher education. Engineering Education, 6 , $39-46$. https://doi.org/10.11120/ened.2011.06020039 
Sawyer, R. 2011. The Impact of New Social Media on Intercultural Adaptation. Senior Honors Projects. University of Rhode Island.

Scialom, M. 2017. How engineers and architects can benefit from HoloLens. Cambridge news.

Shieh, R. S. 2012. The impact of Technology-Enabled Active Learning (TEAL) implementation on student learning and teachers' teaching in a high school context. Computers \& Education, 59, 206-214. http://dx.doi.org/10.1016/j.compedu.2012.01.016

Shirazi, A. \& Behzadan, A. H. 2015. Content Delivery Using Augmented Reality to Enhance Students' Performance in a Building Design and Assembly Project. Advances in Engineering Education: A Journal of Engineering Education Applications 4, 24.

Singer, S. \& Smith, K. A. 2013. Discipline-Based Education Research: Understanding and Improving Learning in Undergraduate Science and Engineering. Journal of Engineering Education, 102, 468-471. https://doi:10.1002/jee.20030

Singer, S. R., Nielsen, N. R., Schweingruber, H. A., Committee on the Status, C. F. D. D. B. E. R., Education, B. S., Education, D. B. S. S. \& Council, N. R. 2012. Discipline-Based Education Research: Understanding and Improving Learning in Undergraduate Science and Engineering, National Academies Press.

Singletary, C. 2017. EON Reality and ORU Open Dedicated AR/VR Learning Facility. UploadVR.

Souza, R. C. \& Kirner, C. 2012. MiniLabElectroMag-AR [Online]. Available: http://ckirner.com/apoio/eletromag/ [Accessed 8.12.2016].

Thorne, S. L. 2008. Transcultural communication in open internet environments and massively multiplayer online games. In: PIERCE, S. M. (ed.) Mediating Discourse Online. John Benjamins Publishing Company. http://dx.doi.org/10.1075/aals.3.17tho

Thorne, S. L., Black, R. W. \& Sykes, J. M. 2009. Second Language Use, Socialization, and Learning in Internet Interest Communities and Online Gaming. The Modern Language Journal, 93, 802-821. http://dx.doi.org/10.1111/j.15404781.2009.00974.x

Thornhill-Miller, B. \& Dupont, J.-M. 2016. Virtual Reality and the Enhancement of Creativity and Innovation: Under Recognized Potential Among Converging Technologies? Journal of Cognitive Education and Psychology, 15, 102-121. https://doi.org/10.1891/1945-8959.15.1.102

Tunstad, H. 2013. Matte bestemmer frafall i skolen. Forskning.no.

Urke, E. H. 2016. Virtual reality-utdanning skal gi 100 arbeidsplasser. Teknisk Ukeblad.

Vardhan, H. 2016. SketchUp Viewer for Microsoft HoloLens is here. Geospatial World.

Vasilescu, B. 2014. Human aspects, gamification, and social media in collaborative software engineering. Companion Proceedings of the 36th International Conference on Software Engineering. Hyderabad, India: ACM. https://doi.org/10.1145/2591062.2591091

Vasileva, S., Vasilev, D. \& Culciar, A. Some opportunities for integrating activities in the creation of electronic textbook. 2016 SAI Computing Conference (SAI), 13-15 July 20162016. 881-885. https://doi.org/10.1109/SAI.2016.7556083

Vassigh, S., Elias, A., Ortega, F. R., Davis, D., Gallardo, G., Alhaffar, H., Borges, L., Bernal, J. \& Rishe, N. D. Integrating Building Information Modeling with Augmented Reality for Interdisciplinary Learning. 2016 IEEE International Symposium on Mixed and Augmented Reality (ISMAR-
Adjunct), 19-23 Sept. $2016 \quad 2016.260-261$ http://dx.doi.org/10.1109/ISMAR-Adjunct.2016.0089

Walker, D. 2017. Microsoft HoloLens release date, rumours, specs \& pricing: HoloLens will beam maintenance data to the International Space Station. IT Pro.

Wu, H.-K., Lee, S. W.-Y., Chang, H.-Y. \& Liang, J.-C. 2013. Current status, opportunities and challenges of augmented reality in education. Computers \& Education, 62, 41-49. http://dx.doi.org/10.1016/j.compedu.2012.10.024

Youyou, W., Kosinski, M. \& Stillwell, D. 2015. Computer-based personality judgments are more accurate than those made by humans. Proceedings of the National Academy of Sciences, 112, 1036-1040. http://dx.doi.org/10.1073/pnas.1418680112 